Western University Scholarship@Western

1970

\title{
The Determinants of the Difference between Bid and Ask Prices on Government Bonds
}

J. Ernest Tanner

Follow this and additional works at: https://ir.lib.uwo.ca/economicsresrpt

Part of the Economics Commons

Citation of this paper:

Tanner, J. Ernest. "The Determinants of the Difference between Bid and Ask Prices on Government Bonds." Department of Economics Research Reports, 7002. London, ON: Department of Economics, University of Western Ontario (1970). 
RESEARCH REPORT 7002

THE DETERMINANTS OF THE DIFFERENCE BETWEEN

BID AND ASK PRICES ON GOVERNMENT BONDS

by

J. Ernest Tanner

March, 1970

Not to be quoted without

the author's permission 
THE DETERMINANTS OF THE DIFFERENCE BETWEEN

BID AND ASK PRICES ON GOVERNMENT BONDS

\author{
by \\ J. Ernest Tanner*
}

\title{
I Introduction
}

The purpose of this paper is to examine statistically the determinants of the spread between bid and ask prices of homogeneous quality bonds in the after market. In particular, we investigate the effects on spread of term to maturity, market yields, coupon rate, and quantity outstanding of a government bond issue. The relationships are studied by using cross section data on Government of Canada debt with maturities ranging from two months to twenty-eight years.

The paper is organized as follows. Section II contains a brief discussion of the general basis for dealer compensation. Based upon this discussion, a number of specific hypotheses about the determinants of spreads are tested in Section III. Section IV compares the results of this testing with evidence on the determinants of spreads found in the United States. A summary concludes the paper.

\section{General Basis for Government Bond Dealers Compensation}

It is well known that the investment dealers perform a number of functions including the underwriting of new debt issues and providing the secondary market facilities which allow the bonds to be fairly liquid. It is this latter function which interests us.

The secondary market is created by the willingness of some two hundred

*I am deeply indebted to Levis Kochin for suggestions and comments, without which this paper would not have been written. 
investment dealers operating in Canada to hold inventories of bonds and to continuously buy and sell. The profit of these dealers results from buying bonds at one price and selling them at a higher price. The spread between bid and ask represents investment dealers profit. Unlike theories of profit maximization of the typical competitive firm, the literature on profit behavior for the investment dealer is almost non existent. A quick survey of the literature, rather than uncovering rigorous analysis for investment dealers ${ }^{8}$ profits, revealed little more than spreads are related to all factors affecting risk which the investment dealer must bear from holding inventories of bonds.

Because an investment dealer performs his risk bearing function by holding inventories of bonds, his gross charge or spread for providing this service must be based upon expectations concerning future developments in securities markets. The primary expected development that most concerns the dealer is the general direction of future movements in the prices of bonds. Unfortunately, very little is really known about how expectations of price movements in the financial markets are formed.

It has frequently been suggested that since it is possible to observe cycles in the behavior of securities prices, the recent past direction and rate of change is probably the primary conditioner of dealers expectations about future prices. For example, Joseph W. Conard argued that in the case of corporate bonds, "it seems reasonable that rising yields (falling prices) in the immediate past might encourage the fear of a further decline in security prices". 1 However, there is a good deal of more recent evidence which indicates that prices in financial markets behave randomly. 2

${ }^{1}$ Joseph W. Conard, The Behavior of Interest Rates, New York: National Bureau of Economic Research, 1966, p. 114 .

2 See, for example, Eugene Fama, "The Behavior of Stock Market Prices," Journal of Business, 38 (Jan. 1965). 
This suggests that the observance of distinct cycles in price behavior in no way implies that accurate predictions about future price movements can be made by studying past price changes. On the contrary, in markets characterized by random price changes, past price behavior provides virtually no useful information about future movements. Thus, to the extent that investment dealers learn from experience, it seems reasonable to assume that their expectations of price change should not be influenced by past price changes.

In addition to being concerned about the general level of securities' prices, investment dealers must also focus on the potential price variability on the particular bond; i.e., its liquidity. It is well known that, in general, a security's liquidity is primarily related to term to maturity and default risk. $^{3}$ However, in this regard, government securities of Canada and the United States are unique because they are not subject to default risk. Nevertheless, government securities share the price level risk common to all fixed income obligations.

In addition, within narrow limits, the issues which appear in the largest volume are more liquid. If the issue is small or obscure, a seller "must expect to face a rather substantial marketing cost and probably some relative discount...".4 Subsequently dealers will require greater compensation for handling issues of small volume. In particular, to the extent that the trading volume is positively related to the quantity of an issue outstanding, the spread will be inversely related to the quantity outstanding of a particular issue of government debt.

${ }^{3}$ See Iva 0. Scott, Government Securities Market; New York: McGraw Hill, 1965, pp. 21-22.

${ }^{4}$ Roland I. Robinson, Postwar Market for State and Local Government Securities, Princeton University Press for the National Bureau of Economic Research, 1960. 


\section{Empirical Testing}

This section attempts an empirical evaluation on the determinants of spread on government bonds from a series of variables which, on a priori grounds, might be expected to influence the spread between bid and ask prices. The model upon which the testing is done is: ${ }^{5}$

$$
S=\alpha+\beta_{m} X_{m}+\beta_{Q} X_{Q}+\beta_{c} X_{c}+\beta_{y} X_{y}
$$

where

$$
\begin{aligned}
& S=\text { dealer spread, in dollars } \\
& x_{m}=\text { term to maturity } \\
& x_{Q}=\text { quantity of issue outs tanding } \\
& x_{c}=\text { coupon rate } \\
& x_{y}=\text { yield to maturity. }
\end{aligned}
$$

Least squares estimates of equation (1) were calculated using both linear and $\log l$ inear forms. The linear specification assumes that the influence of any one independent variable on spread behavior is unrelated to the magnitudes of the remaining explanatory variables. Although this makes for easy application of the results, this specification is not completely satisfactory intuitively because it might be argued that the impact on spreads of a variable like quantity outstanding might be affected by the term to maturity. Consequently, we present estimates of both the linear and $10 \mathrm{~g}-1$ inear relationships.

We now turn to some comments about the particular independent variables selected for inclusion in the regression equations. Iittle need be said about the term to maturity, $\mathrm{x}_{\mathrm{m}}$, except that because the greater the term, the greater is the risk of price change and consequently, the greater the spread. The inclusion of the issue quantity, $\mathrm{x}_{\mathrm{Q}}$, is made to determine the effects issue size have on spread in the secondary market. It has been suggested that the greater

${ }^{5}$ An earlier version of the model included the average of bid and ask prices among the independent variables. Such a specification is improper because coupon rate, maturity date and yield determine the price of a bond. 
the size, the more buyers and sellers there are of an issue and therefore, the more liquid the particular issue. Consequently, it is expected that spread is negatively related to size. 6

Because this study deals with a cross section of government bonds, all are free of default. However, all are subject to price variability and the longer the term to maturity, the further into the future is the date of a "guaranteed return". However, the effective "guaranteed return" may be pushed closer to the present, ceteris paribus, the greater is the coupon rate. Consequently, for a given term to maturity, the price risk will vary inversely with the coupon rate. This would lead us to expect the spread to vary inversely with the coupon rate. On the other hand, the spread would be expected to vary directly with yield to maturity because higher yields probably reflect the intuitive feeling of investors about greater risk (in this case, price risks). Summarizing, the a priori signs of the parameters are $\beta_{\mathrm{m}}>0, \beta_{\mathrm{Q}}<0, \beta_{\mathrm{c}}<0$, and $\beta_{\mathrm{y}}>0$.

The Data and Findings

To test the hypotheses just described, cross section data on the Government of Canada bonds whose market prices are reported each week in the Financial Post were obtained. The data were arranged by term to maturity. Spread data was the difference between the ask and bid prices as reported by the Financial Post on October 25, 1969. The term to maturity was calculated in decimal years from October 1969 to maturity or to the last callable date if the bond is callable after a certain date. The quantity is expressed in millions of dollars outstanding

${ }^{6}$ If issue size is really a determinant of spread, on first blush it might be argued that all government debt should be issued to have one maturity. However, the fact that issue size has a significant effect need not imply that at all for the issuing of government debt depends upon relative costs. More specifically, if information about the market is not available and an issue cannot be "tailored," then the issue size argument would suggest the debt be financed with an issue having one maturity date rather than financing it with a spectrum of maturity dates. 
of a particular bond issue. The coupon rate is calculated as coupons payable: to par value whereas the yield to maturity was calculated by the standard formula which takes account of both coupons and capital gains from the ask price.
A test of the hypotheses are made in equations
(2) and (3).
Equation (2)

is in linear form whereas equation (3) was estimated in $10 \mathrm{~g}$ form

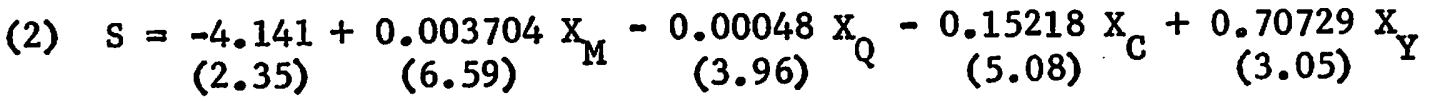

$$
\begin{aligned}
& \mathrm{R}^{2}=0.739 \quad \overrightarrow{\mathrm{R}}^{2}=0.712 \quad \mathrm{~F}=26.950 \quad \text { D.W. }=1.371
\end{aligned}
$$

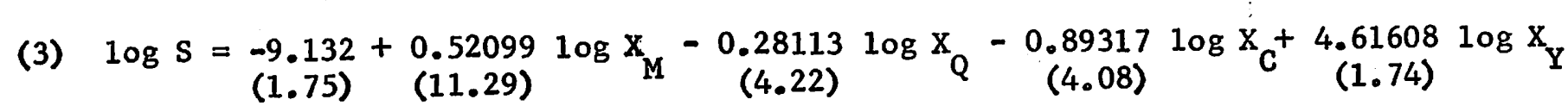

$$
\mathrm{R}^{2}=0.848 \quad \bar{R}^{2}=0.832 \quad \mathrm{~F}=52.975 \quad \mathrm{D}_{\bullet} \mathrm{W}_{\odot}=1.390
$$

In both equations, all explanatory variables have the expected sign and all, save for the $\log$ of yield, $X_{Y}$, are significantly different from zero at the one percent level. Taken together, the independent variables accounted for almost three quarters of the variation in spreads in the linear form, and for 85 percent of the spread variation in the $10 \mathrm{~g}$ linear form. These results indicate that among the determinants of the spread between bid and ask prices of a government debt at a point in time, term to maturity, quantity of the bond issue outstanding, the coupon rate, and the yield to maturity are important explanatory variables.

\section{Comparisons with Other Studies}

To the best of the author's knowledge, this study is the first study to examine investment dealer spread in the after market for government bonds using multi-variant statistical techniques. However, a conceptually similar study of bid and ask spreads on the New York Stock Exchange was done by Harold Demsetz. 7 Using cross section data of January 5 and February 28, 1965 on a random selection

\footnotetext{
7"The Cost of Transacting," Harold Demsetz, Mimeo,, University of Chicago,
} 1968. 
of 200 securities listed on the N.Y.S.E., Demsetz found the following relationship

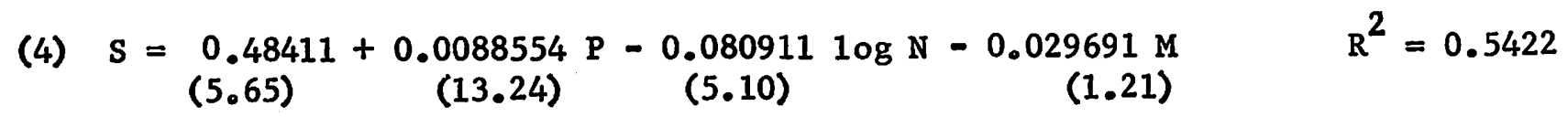

where $\mathbf{P}=$ the price per share

$N=$ the number of shareholders in hundreds

$M=$ the number of markets on which the security was 1isted.

In Demsetz's study, like ours, the fluidity of the market as represented by $\mathrm{N}$ in equation (4) or by $x_{Q}$ in equations (2) and (3) has a significant effect on spread. In explaining his results, Demsetz writes "The dominance of $N$ undoubtedly reflects a strong tendency for $S$ and $P$ to be adjusted to their equilibrium values, so that the...(spread)... does not vary much from one security to another; N, however, does differ between securities and, given the equilibrium cost...,accounts for most of the differences in...(spread)." More specifically, it was found that the spread "declines as trading activity in that security increases." 8

On other issues, our studies are not directly comparable. The coupon rate, the term and yield to maturity are used in ours instead of price and number of markets variables used in Demsetz's study to explain spread. However, our variables combined to produce a better fit than did Demsetz's combination of variables.

V Some Concluding Observations

This study has attempted to examine the empirical relevance of quantitative1y.measurable: features of government bonds in determining the investment dealer spread in the after market at a point in time. By using cross sectional data

\footnotetext{
8 Demsetz, op. cit., p. 24.
} 
and multivariant statistical techniques, we find that 1) there is a significant positive relationship between term to maturity and dealer spread, 2) there is a significant negative relationship between the quantity of an issue outstanding and spread, 3) there is a significant negative relationship between the coupon rate and spread, and finally 4) there is a significant positive relationship between yield to maturity and dealer spread. In conclusion, we should emphasize the fact that the study is based upon cross sectional evidence for a point in time using the Government of Canada debt. Because the sample was taken during a period of very high interest. rates, relative to historical standards, the sample may not be representative of al1 time. 